\title{
RANKING ALTERNATIVES USING PIPRECIA METHOD: A CASE OF HOTELS' WEBSITE EVALUATION
}

\author{
Dragisa STANUJKIC1 ${ }^{*}$, Darjan KARABASEVIC ${ }^{2}$, Gabrijela POPOVIC ${ }^{3}$ \\ ${ }^{1}$ Technical Faculty in Bor, University of Belgrade, Bor, Serbia, dstanujkic@tfbor.bg.ac.rs \\ ${ }^{2}$ Faculty of Applied Management, Economics, and Finance, University Business Academy in Novi Sad, \\ Belgrade, Serbia, darjan.karabasevic@mef.edu.rs \\ ${ }^{3}$ Faculty of Applied Management, Economics, and Finance, University Business Academy in Novi Sad, \\ Belgrade, Serbia, gabrijela.popovic@mef.edu.rs
}

\begin{abstract}
The article presents the application of the PIvot Pairwise RElative Criteria Importance Assessment (PIRECIA) method for ranking alternatives. The PIPRECIA method is primarily intended for determining the significance (weight) of criteria, but it can also be used for completely solving decisionmaking problems. So far, this method has not been used for completely solving multiple criteria decisionmaking problems, which is why this article presents the application of the PIPRECIA method for the evaluation and ranking alternatives. The process of evaluating alternatives using the PIPRECIA method is shown on an example of evaluating the websites of some hotels located in Southern and Eastern Serbia. Keywords: PIPRECIA, website evaluation, websites
\end{abstract}

Original scientific paper

Received: 18.10 .2021

Accepted: 04.11.2021

Available online: 04.11.2021

\section{Introduction}

The PIvot Pairwise RElative Criteria Importance Assessment (PIPRECIA) method is a relatively new multiple criteria decision making (MCDM) method, and it was proposed in 2017 (Stanujkic et al., 2017). The primary purpose of this method is determining the significance (weights) of the evaluation criteria, but it can also be successfully applied for solving MCDM problems, i.e. for evaluating alternatives and selecting the best one.

Although it is a relatively new-proposed method, it has been successfully used for solving some decision-making problems such as: evaluating hotels' websites (Stanujkic et al., 2018), quality control manager selection (Popovic, 2019), ranking of the sustainable indicators for cultural heritage sites (Popovic et al., 2019), assessing the quality of e-learning materials (Jauković-Jocić et al., 2020), personnel selection (Ulutaş et al., 2020), operational performance evaluation in the airline industry (Bakir et al., 2020), and so on.

However, it should be noted that in the aforementioned articles, the PIPRECIA method was used only for determining criteria weights, while other MCDM methods were used for the

${ }^{*}$ Corresponding author 
evaluation of alternatives and selecting the best one. Therefore, in the rest of this article, the application of the PIPRECIA method for the evaluation of the alternative is presented, which is why the rest of the article is organized as follows: Section 1 presents the calculation procedure of the PIPRECIA method, while in section 3 some articles related to the evaluation of the quality of hotels' websites were considered and the criteria used were identified. The use of the PIPRECIA method for determining the quality of hotels' websites is presented in Section 4. Finally, conclusions are given at the end of the article.

\section{The PIPRECIA Method}

The procedure of the PIPRECIA method for determining criteria weights can be accurately presented as follows (Stanujkic et al., 2017):

Step 1. Determine the set of the relevant evaluation criteria and sort them in descending order, based on their expected significance. However, sorting of the criteria is not mandatory and can be omitted.

Step 2. Starting from the second criterion, set the relative significance $s_{\mathrm{j}}$ as follows:

$$
s_{j}=\left\{\begin{array}{cl}
>1 & \text { if } C_{j}>C_{j-1} \\
1 & \text { if } C_{j}=C_{j-1}, \\
<1 & \text { if } C_{j} \prec C_{j-1}
\end{array}\right.
$$

where $C_{j}$ denotes the significance of criterion $j$ and $C_{j-1}$ denotes the significance of the previous $j$ 1 criterion.

Step 3. Calculate the coefficient $k_{j}$ as follows:

$$
k_{j}=\left\{\begin{array}{cc}
1 & \text { if } j=1 \\
2-s_{j} & \text { if } j>1
\end{array}\right.
$$

Step 4. Calculate the recalculated weight $q_{j}$ as follows:

$$
q_{j}=\left\{\begin{array}{cc}
1 & \text { if } j=1 \\
\frac{q_{j-1}}{k_{j}} & \text { if } j>1 .
\end{array}\right.
$$

Step 5. Determine the relative weights of the criteria $w_{j}$ as follows:

$$
w_{j}=\frac{q_{j}}{\sum_{k=1}^{n} q_{k}} .
$$

where $n$ denotes the number of the criteria.

\subsection{The usage of the PIPRECIA methods for ranking alternatives}

The PIPRECIA method can be used for evaluating, i.e. ranking, alternative as in AHP (Saaty, 1980) and SWARA (Kersuliene et al., 2010) methods. In such cases, it is necessary to determine the relative importance of the alternatives concerning each criterion, using the following procedure:

Step 1. Starting from the second alternative, set the relative significance $s$ of alternative $i$ as follows:

$$
s_{i}=\left\{\begin{array}{cl}
>1 & \text { if } A_{i}>A_{i-1} \\
1 & \text { if } A_{i}=A_{i-1}, \\
<1 & \text { if } A_{i}<A_{i-1}
\end{array}\right.
$$

where $A_{i}$ denotes the significance of alternative $i$, and $A_{i-1}$ denotes the significance of the previous $i$-1 alternative. 
Step 3. Calculate the coefficient $k_{i}$ as follows:

$$
k_{i}=\left\{\begin{array}{cc}
1 & \text { if } i=1 \\
2-s_{i} & \text { if } i>1
\end{array} .\right.
$$

Step 4. Calculate $q_{j}$ as follows:

$$
q_{i}=\left\{\begin{array}{cl}
1 & \text { if } i=1 \\
\frac{q_{i-1}}{k_{i}} & \text { if } i>1
\end{array}\right.
$$

Step 5. Determine the relative importance of alternatives concerning the criteria, as follows:

$$
i_{i j}=\frac{q_{i}}{\sum_{k=1}^{m} q_{k}} .
$$

where $i_{i j}$ denotes relative importance of alternative $i$ concerning the criterion $j$, and $\mathrm{m}$ denotes the number of the alternatives.

Steps 1 to 5 are repeated cyclically for each criterion. After that, the utility of each alternative $u_{i}$ is determined as follows:

$$
u_{i}=\sum_{j=1}^{n} i_{i j} w_{j}
$$

After that, the alternatives are ranked according to the value of $u_{i}$, and the alternative with the highest value of $u_{i}$ is declared the best one.

\section{Criteria for Evaluating Websites in the Tourism Industry}

There are numerous studies dedicated to determining the quality of websites in tourism and hospitality. As one of the first studies dedicated to the quality of websites in tourism and hospitality can be mentioned study conducted by Murphy et al. (1996). In their study, they examined many websites at the time and investigated that some of the features available on them.

Chung and Law (2003) proposed an information quality evaluation model for measuring the performance of hotel websites. Their model was based on the use of six evaluation criteria: Facilities information, Customer contact information, Reservation information, Surrounding area information, and Management of websites; as well as the use of their sub-criteria. Law and Cheung (2005) identified five criteria that are important for determining the quality of hotel websites: Reservations information, Facilities information, Contact information, Surrounding area information, and Website management.

Based on a survey of Greek hotel websites, Zafiropoulos and Vrana (2005) identified the following six criteria relevant for determining the quality of hotels' websites: Facilities information, Guest contact information, Reservation and prices information, Surrounding area information, Management of the website and Company profile. For each of these criteria, Zafiropoulos and Vrana (2005) also defined the relevant sub-criteria.

\section{A Numerical Illustration}

In this numerical illustration, the PIPRECIA method was used for determining the criteria weights for evaluating hotels' websites as well as evaluation of the websites of three hotels from Southern and Eastern Serbia.

\subsection{Determining the weights of the criteria selected for evaluating hotel websites}

In this research, the criteria proposed by Zafiropoulos and Vrana (2005) were used for evaluating the quality of hotel websites, i.e.:

- Facilities information $\left(C_{1}\right)$, 
- Guest contact information $\left(C_{2}\right)$,

- Reservation and price information $\left(C_{3}\right)$,

- Surrounding area information $\left(C_{4}\right)$

- Hotel website $\left(C_{5}\right)$, and

- Company profile $\left(C_{6}\right)$

Calculation details obtained during determining criteria weights, using Eqs. (2) to (4), are summarized in Table 1.

Table 1. Calculation details obtained during determining the criteria weights

\begin{tabular}{llccccc}
\hline & Criteria & $\boldsymbol{s}_{j}$ & $\boldsymbol{k}_{j}$ & $\boldsymbol{q}_{j}$ & $\boldsymbol{w}_{j}$ & Rank \\
\hline$C_{1}$ & Facilities information & & 1 & 1 & 0.16 & 3 \\
$C_{2}$ & Guest contact information & 0.9 & 1.1 & 0.91 & 0.15 & 6 \\
$C_{3}$ & Reservation and price information & 1.2 & 0.8 & 1.14 & 0.19 & 1 \\
$C_{4}$ & Surrounding area information & 0.95 & 1.05 & 1.08 & 0.18 & 2 \\
$C_{5}$ & Hotels website & 0.9 & 1.1 & 0.98 & 0.16 & 4 \\
$C_{6}$ & Company profile & 1 & 1 & 0.98 & 0.16 & 4 \\
\hline
\end{tabular}

Source: authors' calculation

From Table 1 it can be seen that the criterion $C_{3}$ - Reservation and price information has the highest weight, as well as that the criterion $C_{5}$ - Hotels website is the fourth-ranked criterion. It should be noted that, in this case, the criteria weights are determined for evaluating websites of hotels located in well-known tourist destinations in Southern and Eastern Serbia.

\subsection{Evaluation of hotels' websites}

Three hotels from Southern and Eastern Serbia were selected for the evaluation of hotels' websites ${ }^{+}$:

- Hotel Balasevic (https://hotelstaraplanina.com/)

- Hotel RAMONDA (https://ramondahotel.com/) i

- Hotel Stara Planina (https://ramondahotel.com/)

The websites of these hotels were evaluated concerning the six criteria mentioned in the previous subsection, using the procedure given in subsection 2.1. Calculation details, calculated using Eqs. (5) to (8), are shown in Tables 2 to 7.

Table 2. The relative importance of alternatives concerning the first criterion

\begin{tabular}{lcccc} 
Alternatives & $\boldsymbol{s}_{\boldsymbol{i}}$ & $\boldsymbol{k}_{\boldsymbol{i}}$ & $\boldsymbol{q}_{\boldsymbol{i}}$ & $\boldsymbol{i}_{\boldsymbol{i}}$ \\
\hline$A_{1}$ & & 1 & 1 & 0.35 \\
$A_{2}$ & 0.95 & 1.05 & 0.95 & 0.34 \\
$A_{3}$ & 0.9 & 1.1 & 0.87 & 0.31 \\
\hline
\end{tabular}

Source: authors' calculation

\footnotetext{
${ }^{\dagger}$ Note: The indices of the alternatives used in this subsection do not match the order in which the hotels are listed.
} 
Table 3. The relative importance of alternatives concerning the second criterion

\begin{tabular}{lcccc}
\hline Alternatives & $\boldsymbol{s}_{i}$ & $\boldsymbol{k}_{i}$ & $\boldsymbol{q}_{i}$ & $\boldsymbol{i}_{\text {i }}$ \\
\hline$A_{1}$ & & 1 & 1 & 0.34 \\
$A_{2}$ & 1 & 1 & 1.00 & 0.34 \\
$A_{3}$ & 0.9 & 1.1 & 0.91 & 0.31 \\
\hline \multicolumn{5}{c}{ Source: authors' calculation }
\end{tabular}

Table 4. The relative importance of alternatives concerning the third criterion

\begin{tabular}{lcccc}
\hline Alternatives & $\boldsymbol{s}_{i}$ & $\boldsymbol{k}_{\boldsymbol{i}}$ & $\boldsymbol{q}_{\boldsymbol{i}}$ & $\boldsymbol{i}_{\text {i3 }}$ \\
\hline$A_{1}$ & & 1 & 1 & 0.34 \\
$A_{2}$ & 1.2 & 0.8 & 1.25 & 0.43 \\
$A_{3}$ & 0.9 & 1.1 & 1.14 & 0.39 \\
\hline \multicolumn{4}{c}{ Source: authors' calculation }
\end{tabular}

Table 5. The relative importance of alternatives concerning the fourth criterion

\begin{tabular}{lcccc}
\hline Alternatives & $\boldsymbol{s}_{i}$ & $\boldsymbol{k}_{\boldsymbol{i}}$ & $\boldsymbol{q}_{\boldsymbol{i}}$ & $\boldsymbol{i}_{i 4}$ \\
\hline$A_{1}$ & & 1 & 1 & 0.34 \\
$A_{2}$ & 1.4 & 0.6 & 1.67 & 0.57 \\
$A_{3}$ & 0.5 & 1.5 & 1.11 & 0.38 \\
\hline
\end{tabular}

Source: authors' calculation

Table 6. The relative importance of alternatives concerning the fifth criterion

\begin{tabular}{lcccc}
\hline Alternatives & $\boldsymbol{s}_{\boldsymbol{i}}$ & $\boldsymbol{k}_{\boldsymbol{i}}$ & $\boldsymbol{q}_{\boldsymbol{i}}$ & $\boldsymbol{i}_{i 5}$ \\
\hline$A_{1}$ & & 1 & 1 & 0.34 \\
$A_{2}$ & 1.2 & 0.8 & 1.25 & 0.43 \\
$A_{3}$ & 0.6 & 1.4 & 0.89 & 0.31 \\
\hline
\end{tabular}

Source: authors' calculation

Table 7. The relative importance of alternatives concerning the fifth sixth criterion

\begin{tabular}{lcccc}
\hline Alternatives & $\boldsymbol{s}_{i}$ & $\boldsymbol{k}_{\boldsymbol{i}}$ & $\boldsymbol{q}_{\boldsymbol{i}}$ & $\boldsymbol{i}_{i 6}$ \\
\hline$A_{1}$ & & 1 & 1 & 0.34 \\
$A_{2}$ & 1.1 & 0.9 & 1.11 & 0.38 \\
$A_{3}$ & 0.8 & 1.2 & 0.93 & 0.32 \\
\hline
\end{tabular}

Source: authors' calculation

Based on the data from Table 1 and Tables 2 to 7 , an initial decision matrix was formed which contains the weights of the criteria and the relative importance of alternatives concerning the criteria. The initial decision matrix was shown in Table 8. 
Table 8. Initial decision matrix

\begin{tabular}{ccccccc}
\hline & $C_{1}$ & $C_{2}$ & $C_{3}$ & $C_{4}$ & $C_{5}$ & $C_{6}$ \\
\hline$w_{j}$ & 0.16 & 0.15 & 0.19 & 0.18 & 0.16 & 0.16 \\
\hline$A_{1}$ & 0.35 & 0.34 & 0.34 & 0.34 & 0.34 & 0.34 \\
$A_{2}$ & 0.34 & 0.34 & 0.43 & 0.57 & 0.43 & 0.38 \\
$A_{3}$ & 0.31 & 0.31 & 0.39 & 0.38 & 0.31 & 0.32 \\
\hline
\end{tabular}

Source: authors' calculation

Finally, the utility of each alternative is calculated using Eq. (9), as is shown in Table 9.

Table 9. Utility and ranking order of alternative

\begin{tabular}{ccccccccc}
\hline & $C_{1}$ & $C_{2}$ & $C_{3}$ & $C_{4}$ & $C_{5}$ & $C_{6}$ & $u_{i}$ & Rank \\
\hline$A_{1}$ & 0.058 & 0.051 & 0.064 & 0.061 & 0.055 & 0.055 & 0.346 & 2 \\
$A_{2}$ & 0.055 & 0.051 & 0.080 & 0.102 & 0.069 & 0.062 & 0.420 & 1 \\
$A_{3}$ & 0.050 & 0.047 & 0.073 & 0.068 & 0.050 & 0.051 & 0.339 & 3 \\
\hline
\end{tabular}

Source: authors' calculation

From Table 9 it can be seen that the hotel denoted as $A_{2}$ has the best website. In a competitive environment, a website can provide certain advantages, such as getting guests and online booking, which is why hotels denoted as $A_{1}$ and $A_{3}$ should improve their presentations. We intentionally ddid not emphasize wich hotel has the best website presentation to avoid its promotion.

\section{Conclusion}

The use of the PIPRECIA method for the evaluation and ranking of alternatives is presented in this article. The evaluation is shown on an example of evaluation and ranking websites of some hotels located in Southern and Eastern Serbia.

From the presented example, it can be concluded that the process of evaluating alternatives using the PIPRECIA method is not complex and can therefore be applied for solving similar problems. In addition, the evaluation process using the PIPRECIA method is based on pairwise comparisons, which can make it easier for decision-makers, or respondents, to express their attitudes. Proposed method facilitates a decision-making process and enables decision-makers to find an optimal solution regarding to the existing conditions. In this case, the PIPRECIA is applied in the case of the selection the best website of the hotel, but its potential should be observed and tested in other business fields, as well.

\section{Acknowledgments}

The research presented in this article was done with the financial support of the Ministry of Education, Science and Technological Development of the Republic of Serbia, within the funding of the scientific research work at the University of Belgrade, Technical Faculty in Bor, according to the contract with registration number 451-03-9/2021-14/ 200131 


\section{References}

Bakir, M., Akan, Ş., Kiraci, K., Karabasevic, D., Stanujkic, D., \& Popovic, G. (2020). Multiplecriteria approach of the operational performance evaluation in the airline industry: Evidence from the emerging markets. Romanian Journal of Economic Forecast, 23, 149.

Chung, T., \& Law, R. (2003). Developing a performance indicator for hotel websites. International journal of hospitality management, 22(1), 119-125.

https://hotelstaraplanina.com/ (18.10.2021.)

https://ramondahotel.com/ (18.10.2021.)

https://www.balasevicrtanj.com/ (18.10.2021.)

Jauković-Jocić, K., Karabašević, D., \& Jocić, G. (2020). The use of the PIPRECIA method for assessing the quality of e-learning materials. Ekonomika, 66(3), 37-45.

Keršuliene, V., Zavadskas, E.K., \& Turskis, Z. (2010). Selection of rational dispute resolution method by applying new step-wise weight assessment ratio analysis (SWARA). Journal of business economics and management, 11(2), 243-258.

Law, R., \& Cheung, C. (2005) Weighing of hotel website dimensions and attributes. In: FREW, A.J. (Ed.). Information and communication technologies in tourism. New York: Springer Wien, 2005. (pp. 350-359).

Murphy, J., Forrest, E. J., Wotring, C. E., \& Brymer, R. A. (1996). Hotel management and marketing on the Internet: An analysis of sites and features. The Cornell Hotel and Restaurant Administration Quarterly, 37(3), 7-82.

Popovic, G. (2019). A framework for the quality control manager selection based on the PIPRECIA and WS PLP methods. In Third International Scientific Conference on Economics and Management-EMAN 2019: How to Cope with Disrupted Times-Selected Papers, Ljubljana, Slovenia-March 28, pp. 33-44.

Popovic, G., Stanujkic, D., Karabasevic, D., Maksimovic, M., \& Sava, C. (2019). Multiple criteria approach in the ranking of the sustainable indicators for cultural heritage sites. Quaestus, $14,165-175$.

Saaty, L.T. (1980). The Analytic Hierarchy Process. McGraw Hill Company, New York, NY, USA.

Stanujkic, D., Karabasevic, D., \& Cipriana, S. A. V. A. (2018). An application of the PIPRECIA and WS PLP methods for evaluating website quality in hotel industry. Quaestus, 12, 190-198.

Stanujkic, D., Zavadskas, E.K., Karabasevic, D., Smarandache, F., Turskis, Z. (2017). The use of the pivot pairwise relative criteria importance assessment method for determining the weights of criteria. Romanian Journal of Economic Forecasting, 20, 116-133.

Ulutaş, A., Popovic, G., Stanujkic, D., Karabasevic, D., Zavadskas, E. K., \& Turskis, Z. (2020). A new hybrid MCDM model for personnel selection based on a novel grey PIPRECIA and grey OCRA methods. Mathematics, 8(10), 1698.

Zafiropoulos, C., \& Vrana, V. (2006). A framework for the evaluation of hotel websites: The case of Greece. Information Technology \& Tourism, 8(3-4), 239-254. 